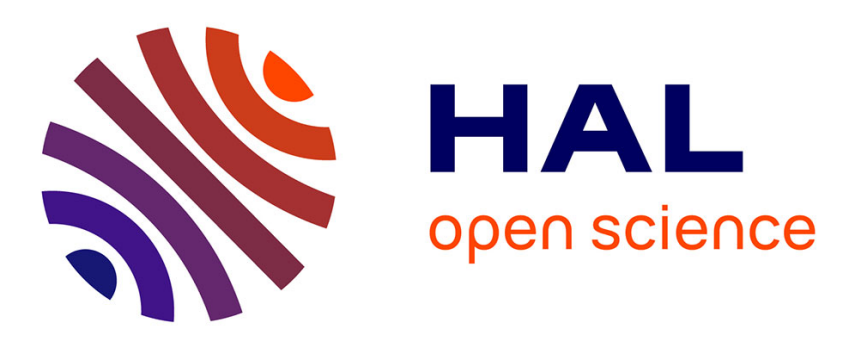

\title{
Experimental study of a six new ball-burnishing strategies effects on the Al-alloy flat surfaces integrity enhancement
}

Hatem Amdouni, Hassen Bouzaiene, Alex Montagne, Adrien van Gorp, Thierry Coorevits, Mustapha Nasri, Alain Iost

\section{To cite this version:}

Hatem Amdouni, Hassen Bouzaiene, Alex Montagne, Adrien van Gorp, Thierry Coorevits, et al.. Experimental study of a six new ball-burnishing strategies effects on the Al-alloy flat surfaces integrity enhancement. Int. J. Adv. Manuf. Technol, 2017, 90, pp.2271-2282. 10.1007/s00170-016-9529-9 . hal-03169212

\section{HAL Id: hal-03169212 \\ https://hal.science/hal-03169212}

Submitted on 15 Mar 2021

HAL is a multi-disciplinary open access archive for the deposit and dissemination of scientific research documents, whether they are published or not. The documents may come from teaching and research institutions in France or abroad, or from public or private research centers.
L'archive ouverte pluridisciplinaire HAL, est destinée au dépôt et à la diffusion de documents scientifiques de niveau recherche, publiés ou non, émanant des établissements d'enseignement et de recherche français ou étrangers, des laboratoires publics ou privés. 


\title{
Experimental study of a six new ball-burnishing strategies effects on the Al-alloy flat surfaces integrity enhancement
}

\author{
Hatem Amdouni $^{1}$ • Hassen Bouzaiene ${ }^{2}$ - Alex Montagne ${ }^{3}$ - Adrien Van Gorp ${ }^{3}$. \\ Thierry Coorevits ${ }^{3}$ - Mustapha Nasri $^{1}$ - Alain Iost ${ }^{3}$
}

\begin{abstract}
In the literature, the most studies conducted on the flat surface ball-burnishing process have been focused on the most important classical factors like burnishing speed, lateral feed, and the ball-burnishing load or pressure on the treated surfaces integrity enhancement. In this research, ballburnishing strategies are studied as a new ball-burnishing factor. The aim of this research is to show the improvement of the flat surface integrity of 2017A-T451 aluminum alloy using six new ball-burnishing strategies. Ball-burnishing tests were conducted in two passes using the recommended values of the ball-burnishing factors (the penetration depth $a_{b}$ is
\end{abstract}

Hatem Amdouni

hatemamdouni@gmail.com

Hassen Bouzaiene

bouzaiene.hassen@gmail.com

Alex Montagne

alex.montagne@ensam.eu

Adrien Van Gorp

adrien.vangorp@ensam.eu

Thierry Coorevits

thierry.coorevits@ensam.eu

Mustapha Nasri

Mustapha.Nasri@isetn.rnu.tn

Alain Iost

alain.iost@lille.ensam.fr

1 Laboratoire de Photométrie, IPEIN, BP 62 Merazka, 8000 Nabeul, Tunisia

2 Research Units in Solid Mechanics, Structures and Technological Development (99-UR11-46), ENSIT, Tunis, Tunisia

3 Arts et Métiers ParisTech, MSMP, 8 boulevard Louis XIV, 59000 Lille, France
$40 \mu \mathrm{m}$, the linear ball-burnishing speed $V_{b}$ is $500 \mathrm{~mm} / \mathrm{min}$ and a lateral feed $f$ of $0.2 \mathrm{~mm}$ ). Two ball-burnishing strategies in two successive and perpendicular passes to the machining direction and four ball-burnishing strategies in two crossed passes have been designed and tested to improve the flat surfaces integrity of the samples. The characterization and the micrographic observations of the ball-burnished surfaces show that using the best ball-burnishing strategy leads to a great enhancement in surface quality. The latter is predicted by a gain in average roughness Ra of $81 \%$, an improvement in the mean spacing of profile irregularities $\mathrm{Sm}$ of $34 \%$, an enhancement in surface Nano-hardness HIT of $17 \%$, and sub-layer hardness betterment up to a depth of $500 \mu \mathrm{m}$.

Keywords Ball-burnishing strategy $\cdot$ Roughness ·

Nano-hardness $\cdot$ SEM micrograph $\cdot$ Aluminum alloy

\section{Introduction}

Ball-burnishing process is a mechanical surface treatment, eventually used for the finishing of functional mechanical surfaces [1]. It is widely practiced following the machining of the cylindrical surfaces [2], spherical [3], concave or convex [4], flat [5, 6], or complex surfaces [7] of mechanical parts. This post-machining and low-cost finishing process is often applied to improve the surface integrity of aluminum alloys, which are difficult-to-grind with the high-cost conventional grinding as mentioned in the work of El-Axir et al. [8]. In addition, as a solution of the latter problem, Bouzid et al. have shown that the ball-burnishing surface treatment process can easily replace grinding in the machining range of the mechanical part production [9].

This mechanical surface finishing technology without material removal consists in the crash of the surface 
geometric irregularities roughness under the effect of a normal pressure applied by a rigid rolling or sliding ball against the machined surface as shown in Adnan Akkurt study, inducing thereby a cold plastic deformation of the roughness peaks and pushing them into the hollow of the surface roughness profile [10]. So, this process makes smooth and hard the machined surface as indicated in the work of Hassan (1997) and eliminating at the same time the potential priming sites of cracks (the roughness hollow) [11]. In addition, by forming an incompatibility of plastic deformation between the surface and the rest of the material part, a compressive residual stresses are formed to a depth of up to $1 \mathrm{~mm}$ in depth as investigated in the research conducted by Hassan and AI-Wahhab in 1998 [12].

As for the other shapes of surface, the successful application of the ball-burnishing process in order to improve the flat surface integrity needs the mastery, the study, and the optimization of several factors related to the mechanical surface treatment technology as shown in the literature survey and discussion paper of Loh and Tam [1]. The most significant factors studied by researchers for the flat surfaces finishing by ball-burnishing are in order of interest, feed rate or the overlap or also called lateral feed, the penetration depth, and the linear burnishing speed which are the necessary factors for the flat surface sweeping.

With a second interest, several other process-related factors have been studied by researchers namely ball material, ball diameter, lubricant, ball-surface contact pressure, kind of the ball-surface contact, initial roughness of the machined surface, the normal burnishing load, the number of passes, and the surface sweeps strategy (ball-burnishing tool path).

A classification of the flat surface ball-burnishing factors is proposed in Fig. 1. The latter show that all ballburnishing factors related to the finishing process can be classified in four groups. The first one is formed by the ball-burnishing factors associated to the kinematics of the roller ball relative to the flat surface such as burnishing speed, lateral feed, kind of ball/surface contact, and the ball-burnishing strategies (tool path). The second is associated to ball-burnishing factors necessary for the hardening of the flat treated surface namely penetration depth, the normal load, hydraulic pressure, the number of passes, and lubricant. The third group is formed by the ballburnishing factors associated to the ball characteristics like ball diameter and ball material. Finally, the fourth group is associated to the treated surface propriety as the initial roughness and material properties.

The measurable responses of the treated surfaces by ball-burnishing such as hardness and roughness are nonlinear [13]. Then, the optimization of these mechanical greatness is necessary in each application of the process to establish the optimum ball-burnishing factors giving the better surface integrity. By using the Taguchi
Method, an optimization with experimental design of a freeform surface roughness of plastic injection mold was established by Shiou and Chen for studying the contribution of the four ball-burnishing process factors (ball material, burnishing speed, burnishing force, and feed rate) on the finished surface roughness [14]. Afterward, optimal conditions were applied on a pocket mold surface. Then, average roughness enhancement was established about $63 \%$ for the flat surface and $78 \%$ for free-form surface.

Loh et al. have shown that ball material, lubricant, lateral feed, and depth of penetration are the significant factors at a $99 \%$ confidence level on the roughness enhancement by ball burnishing of the flat surfaces of AISI 1045 steel specimens [15]. The application of optimal process factors has allowed the team to achieve a $400 \%$ improvement in the treated surface roughness. The machined surface roughness of $4 \mu \mathrm{m}$ (Rtm) was finished by ball burnishing to $0.772 \mu \mathrm{m}$.

As shown in their work, Salahshoor and Guo have used the ball-burnishing process on flat samples to improve the corrosion resistance of the biodegradable magnesiumcalcium $(\mathrm{MgCa})$ alloy, often used in the manufacture of dental implants [16]. They showed that the roughness of the burnished surfaces is anisotropic. This anisotropy increases with the increasing of burnishing pressure and burnishing lateral feed. The lower anisotropy and the best roughness are obtained by applying a ball-burnishing strategy designed with two crossed passes. In this case, ball-burnishing process has been applied under medium pressure, with a low lateral feed and a slow burnishing speed. A much improvement of the ball-burnishing surfaces micro-hardness ranges from the surface to $500 \mu \mathrm{m}$ of the subsurface. Unlike roughness, surface hardness is isotropic. The increase in burnishing pressure causes the decrease in surface hardness, while the rolling speed, the lateral feed, and burnishing strategy have poor effects. Also, an additional pass degrades the surface hardness by chipping formation.

The application of the ball-burnishing process for surface finishing of P20 heat-treated steel (often used in the manufacture of molds and dies) and Inconel 718 has allowed López de Lacalle et al. to get a high-quality mirror-like surface $(R a=0.071 \mu \mathrm{m})$ [3]. The lowest arithmetic roughness $\mathrm{Ra}$ is obtained when the ball burnishing is applied at perpendicular direction to milling.

So, the mechanical cold work hardening of the surface, the great improvement of the surface roughness, the increasing in micro-hardness surface, and the introduction of compressive residual stress in sub-layers are the sources of surface integrity gains. The latter is described by an improvement in the fatigue strength, an increase in corrosion resistance as demonstrated in Prevéy et 
Fig. 1 Flat surface ballburnishing factors classification

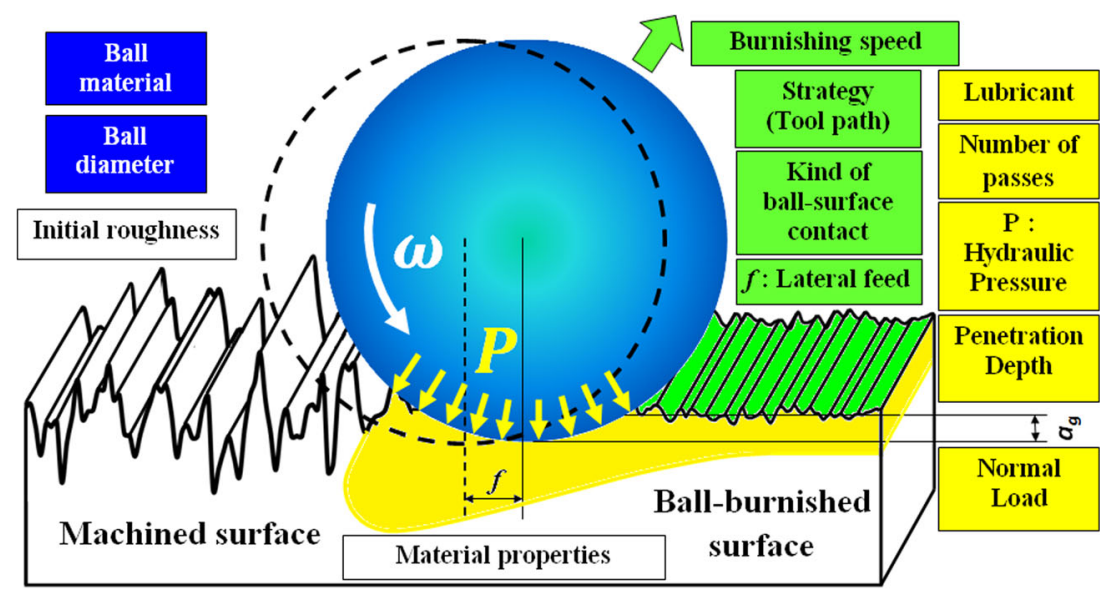

Ball-burnishing factors associated to the kinematics of the roller ball relative to the flat surface.

Ball-burnishing factors associated to the hardening of the treated surface.

Ball-burnishing factors associated to the roller ball properties.

Ball-burnishing factors associated to the treated surface properties.
Cammett publication [17]. In addition, a tribological behavior betterment of the treated surfaces described by the enhancement of the wear resistance of mechanical parts has been shown in the work of Hassan et al. [18]. Furthermore, the ball-burnishing load, which is responsible for the surface and sub-layer hardening of the treated surface as indicated in Rodríguez et al. work [19], is the major factor affecting the improvement of the wear resistance of the samples steel as demonstrated in the study of Rajasekariah and Vaidyanathan [20]. Also, a wear increase was observed by Neema and Pandey in the case of excessive increase in the load and number of passes during the ball burnishing of metallic surfaces [21].

In this process, there is an interaction between the ball diameter and the burnishing applied load. An increase in the ball diameter coupled with the increase in ball-burnishing load leads to a deterioration of the treated surfaces predicted by the increase in roughness and degradation of the surface hardness and therefore, consequently, an increased surface wear as shown in Hassan and Maqableh study [22].

Generally improving fatigue life, wear, and corrosion resistance is the result of the improvement of the treated flat surfaces integrity through research, mastering, and optimization of significant ball-burnishing factors. Great interests in the influence study of the classical ball-burnishing factors (lateral feed, burnishing speed, and the depth of penetration) were given by researchers to improve the flat surfaces integrity. Moreover, only one study has compared the effect of using two ball-burnishing strategies for finishing flat surfaces as shown in Salahshoor and Guo study [16]. The authors have shown that ball-burnishing strategy in two crossed ZIG/
ZAG passes has greater potential in improving the flat surfaces integrity than that of the two successive and perpendicular ZIG/ZAG passes to machining direction.

In addition in their work, Amdouni et al. have conducted a modeling and an optimization study of a new ball-burnishing strategy, in two crossed passes, to investigate the influence of three classical ball-burnishing factors (burnishing speed, depth of penetration, and lateral feed) on the 2017A-T451 aluminum alloy flat machined surface integrity enhancement [13]. Optimized surface has led to mirror-like surface quality characterized by an improvement in average roughness Ra of $81 \%$, an enhancement in the mean spacing of profile irregularities Sm of $34 \%$, and a gain in surface nano-hardness HIT of $17 \%$.

This existing gap in the literature for the study of the ballburnishing strategy effects is explained by the use of a single pass for the finishing of flat surfaces in the most research on this subject as indicated in Shiou and Hsu [23] In this study, we reveal the influence of the application of six new ballburnishing strategy for improving the aluminum alloy flat surfaces integrity.

\section{Experimental work}

\subsection{Specimen preparation and ball-burnishing operations}

Experimental work conducted in this study has the objective of the application of six ball-burnishing strategies on a flat machined surface. Then, a plate of size $1290 \times 310 \times 10 \mathrm{~mm}$ of a 2017A-T451 aluminum alloy of which chemical composition and mechanical characteristics are shown in Tables 1 and 2 was used. 
Table 1 Chemical composition of 2017A-T451 aluminum alloy
Chemical composition of 2017A-T451

\begin{tabular}{lllllllllll}
\hline Elements & $\mathrm{Al}$ & $\mathrm{Si}$ & $\mathrm{Fe}$ & $\mathrm{Cu}$ & $\mathrm{Mn}$ & $\mathrm{Mg}$ & $\mathrm{Cr}$ & $\mathrm{Zn}$ & $\mathrm{Zr}+\mathrm{Ti}$ & Others total \\
\hline wt\% & Rest & 0.76 & 0.7 & 3.82 & 0.54 & 0.67 & 0.1 & 0.25 & 0.25 & 0.15 \\
\hline
\end{tabular}

As shown in Fig. 2, the machining of $85 \times 60 \times 10-\mathrm{mm}$ size sample and the surface treatment by ball-burnishing, according to the parameters shown in Table 3, was performed on the same three axes $\mathrm{CNC}$ machining center SPINNER VC650. A ball-burnishing tool providing a rolling contact between the rigid ball of $14 \mathrm{~mm}$ of diameter and the flat machined surface was designed as shown in Fig. 2a, b. The circular pocket in which are housed five intermediate balls underwent a hard chrome coating to improve friction and to avoid the balls wear. In addition, as shown in Fig. 2a, the contact between the five intermediate balls (5) and the circular pocket surfaces as well as that between the five intermediate balls (5) and the main ball (4) are greased using the bearing K2K-30 grease in accordance with the standard DIN 51825.

The surfaces quality evaluation of the machined and the ball-burnished ones are done by the measurements of roughness plots parameters using the optical interferometric profilometer Veeco Wyko NT9300 according to the Standard ISO 4287, (1997) for Geometrical Product Specifications (GPS). Furthermore, the evaluation of the surface hardness and hardness sub-layer gradient of the six ball burnished surfaces as well as that machined, nano-indenter XP MTS was used in classic mode indentation in charge-discharge. This device enables to indent the surface of the sample to be characterized with a Berkovich tip of high rigidity. The dry machining of the flat surface was conducted with a cutter milling tool having a $63 \mathrm{~mm}$ as a diameter and equipped with a three reported carbide inserts (TCMT 110204) with a frequency spindle $N=960 \mathrm{rpm}$, a feed rate $f_{m}=384 \mathrm{~mm} / \mathrm{min}$, a depth of penetration $a_{f}=0.4 \mathrm{~mm}$, a tooth feed-rate $f z=0.08$ $\mathrm{mm} / \mathrm{r}$.tooth and a cutting speed $V_{c}=190 \mathrm{~m} / \mathrm{min}$.

Successively, on the same machining center CNC, six ball-burnishing strategies, of size $20 \times 20 \mathrm{~mm}$, developed in Fig. 3 were applied on the machined flat surface following the recommended and optimum ball-burnishing factors (the linear ball-burnishing speed $V_{b}=500 \mathrm{~mm} /$ min, the penetration depth $a_{b}=40 \mu \mathrm{m}$, and a lateral feed $f=0.2 \mathrm{~mm}$ ) as shown in Fig. 4 and as investigated in Amdouni et al. study [13].

\subsection{Design of six ball-burnishing strategies}

Whatever the number of passes applied for finishing a flat surface by ball-burnishing, the final finishing pass must be applied perpendicular to the machining direction of the treated surface as mentioned in the works of Sequera et al. [6] and Salahshoor et al. [16]. In each ball-burnishing pass on the flat machined surfaces, the rolling without slipping of the ball can be practiced in two different cycles previously programmed on the $\mathrm{CNC}$ machining center.

During the cycle named ZIG/ZAG which is the most used by researchers [23], the roller ball keeps contact with the machined surface for a ZIG/ZAG scanning by making a back and come movement as shown in the work of Salahshoor et al. [16]. But, a different cycle called SEUIL can be practiced only in one direction while losing the contact between the ball and the surface during the lateral movement phase.

The finishing possibility of flat surfaces by ball-burnishing using two different cycles of the ball displacement available on the machining center $\mathrm{CNC}$ has allowed us to imagine the six ball-burnishing strategies as shown in Fig. 3.

- Strategy 1: strategy ZIG/ZAG in two perpendicular successive passes to the milling direction of the flat surface ( $X$-axis).

- Strategy 2: strategy SEUIL in two perpendicular successive passes to milling direction of the flat surface ( $X$-axis).

- Strategy 3: Strategy ZIG/ZAG in two crossed passes, a first parallel pass followed by a second perpendicular pass to the cutting direction ( $X$-axis).

- Strategy 4: Strategy SEUIL in two crossed passes, a first parallel pass followed by a second perpendicular pass to the cutting direction ( $X$-axis).

- Strategy 5: Strategy SEUIL_ZIG/ZAG in two crossed passes, a first parallel SEUIL pass followed by a second perpendicular ZIG/ZAG pass to the cutting direction ( $X$-axis).
Table 2 Mechanical properties of 2017A-T451 aluminum alloy

\begin{tabular}{lllll}
\hline $\begin{array}{l}\text { Rm-Tensile } \\
\text { strength (MPa) }\end{array}$ & $\begin{array}{l}R p_{0.2} 0.2 \% \text { proof } \\
\text { strength }(\mathrm{MPa})\end{array}$ & $\begin{array}{l}\text { A-Min. elongation } \\
\text { at fracture }(\%)\end{array}$ & $\begin{array}{l}\text { Brinell hardness } \\
(\mathrm{HBW})\end{array}$ & $\begin{array}{l}\text { Young's } \\
\text { module (MPa) }\end{array}$ \\
\hline 427 & 272 & 12 & 105 & 72,500 \\
\hline
\end{tabular}


Fig. 2 Experimental setup: a ball-burnishing tool design, body (1), screw (2), blocking screw (3), principal ball $14 \mathrm{~mm}$ of diameter (4), and five intermediate balls $7 \mathrm{~mm}$ of diameter (5); b ballburnishing tool mounted on $\mathrm{CNC}$ Milling Collet Chuck (6); and c application of ball-burnishing process, CNC Vise Clamps (7) and sample $(8)$
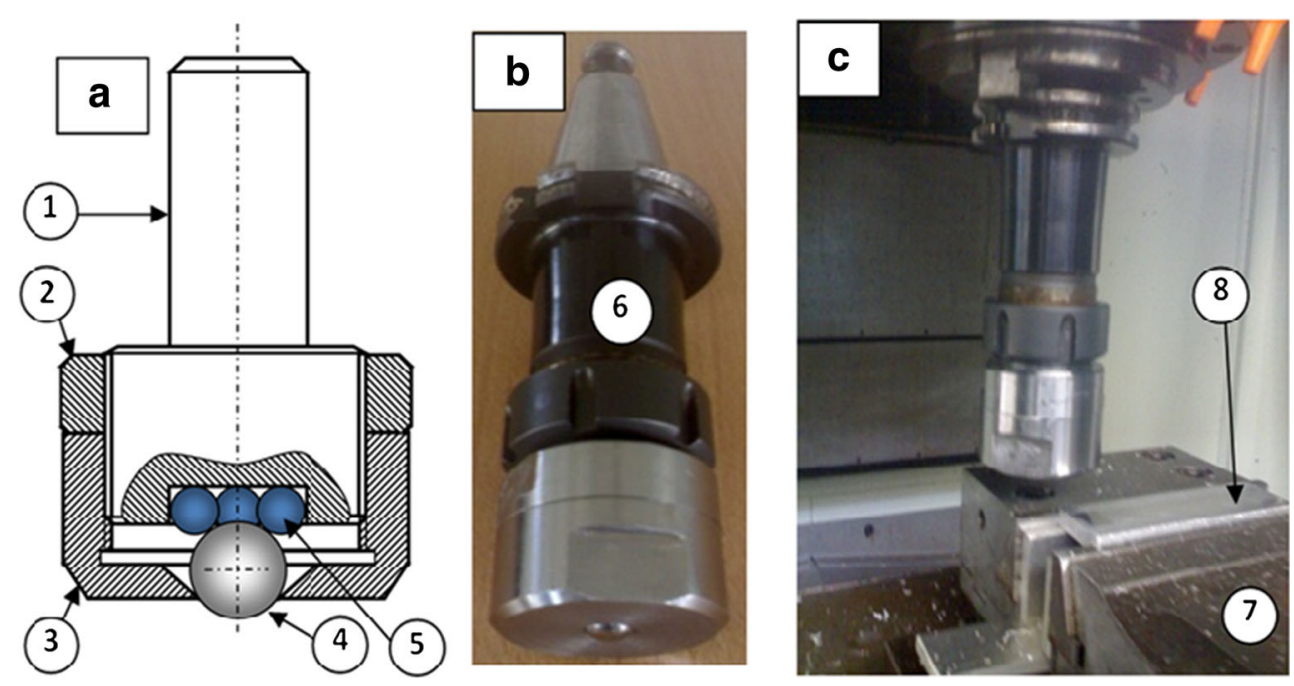

- All tested surfaces show that the roughness parameters measured in the $X$ direction are greater than those measured along the perpendicular direction; this is due to the anisotropy of the initial surface finish (machined surface).

- Comparison of both ball-burnishing strategies in two successive and perpendicular passes to the machining direction reveals that the strategy (2) is better than strategy (1) in reducing the surface roughness of the machined surface.

- By exception of the strategy (3), the ball-burnishing strategies in two crossed passes have better potential for improving the roughness than the first two successive strategies. Strategy (6) has the best capability for reducing and improving surface roughness.

- The best potential improvement of roughness carried out with the strategy (6) results in a gain of $81 \%$ for Ra, $84 \%$ for Rq, $82 \%$ for Rz, and $81 \%$ for Rt.

Tested surfaces roughness anisotropy was quantified by the difference between the roughness parameter values measured in the $X$ direction of machining and those along the perpendicular direction. The latter represented in Fig. 6 shows that
Milling flat surface

\begin{tabular}{|c|c|c|c|c|c|}
\hline Parameter & Symbol & Quality & Parameter & Symbol & Quality \\
\hline Face milling cutter diameter & $D f$ & $63 \mathrm{~mm}$ & Ball material & & Chromed 100Cr6 \\
\hline Three carbide inserts & & TCMT 110204 & Ball diameter & $\varnothing_{\text {ball }}$ & $14 \mathrm{~mm}$ \\
\hline Spindle frequency & $N$ & $960 \mathrm{r} / \mathrm{min}$ & Contact ball/surface & & Rolling \\
\hline Feed rate & $f_{m}$ & $384 \mathrm{~mm} / \mathrm{min}$ & Number of passes & $N_{P}$ & 2 \\
\hline Penetration of cut & $a_{f}$ & $0.4 \mathrm{~mm}$ & Burnishing speed & $V_{b}$ & $500 \mathrm{~mm} / \mathrm{min}$ \\
\hline Feed per tooth & $f_{z}$ & $0.08 \mathrm{~mm} /$ tooth & Depth of penetration & $a_{b}$ & $40 \mu \mathrm{m}$ \\
\hline Cutting speed & $V_{c}$ & $190 \mathrm{~m} / \mathrm{min}$ & Lateral feed & $f$ & $0.2 \mathrm{~mm}$ \\
\hline Lubricant & & none & Lubrifiant & & none \\
\hline
\end{tabular}

Table 3 Milling and ball-burnishing flat surface experimental parameters

Ball-burnishing of machined surface surfaces are able to improve the roughness parameters measured according to the cutting direction of the samples. 


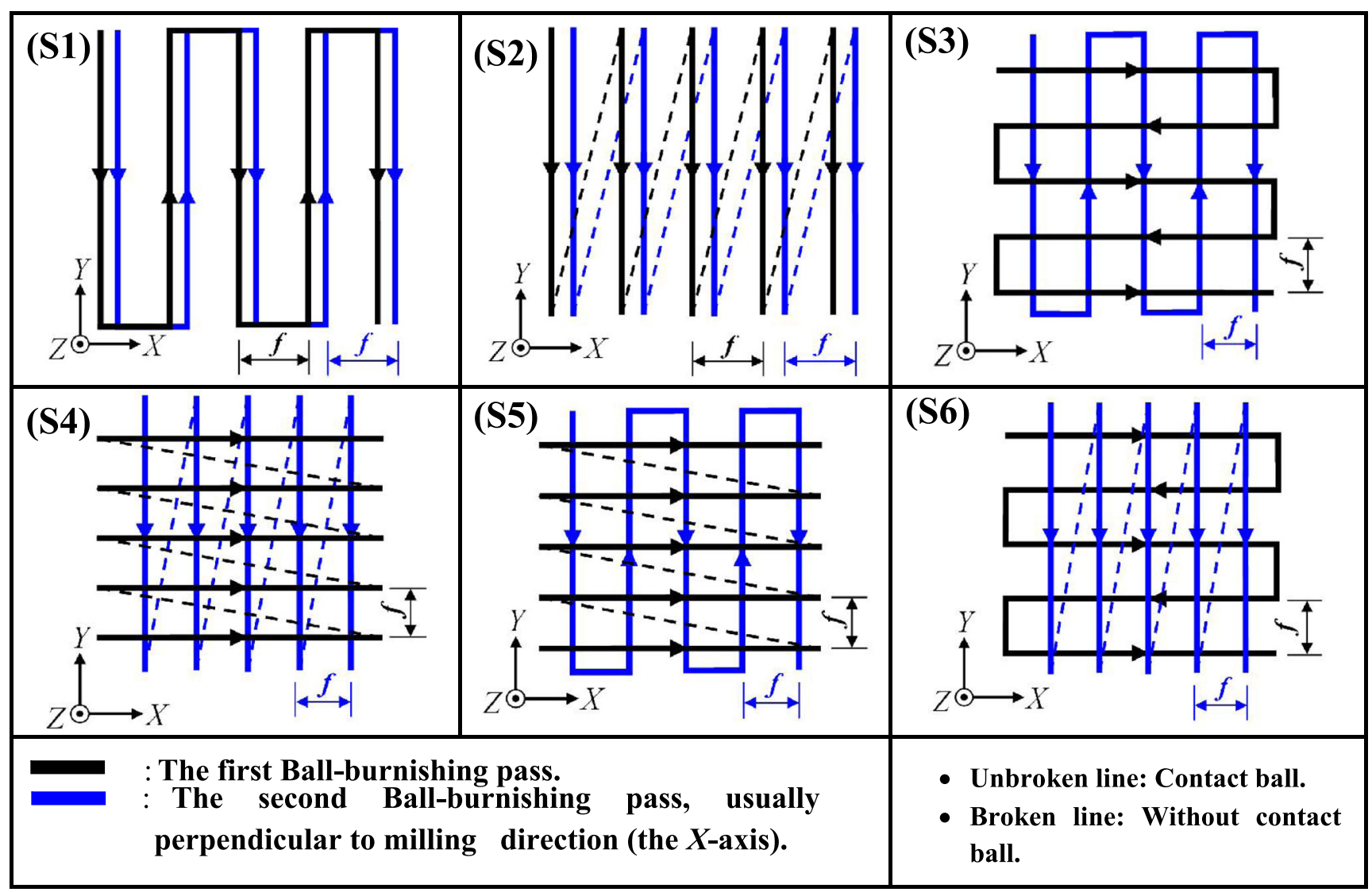

Fig. 3 Design of the six ball-burnishing strategies

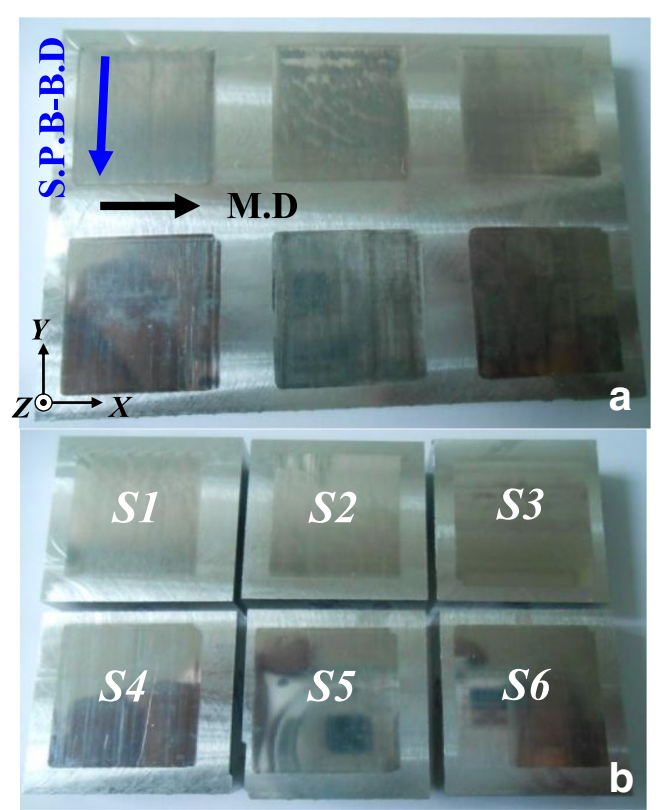

Fig. 4 Samples preparations: a application of the six ball-burnishing strategies, the second pass ball-burnishing direction (S.P.B-B.D), the milling direction (M.D); and $\mathbf{b}$ separation of the six ball-burnishing strategies for surface characterizations the strategy (6) gives the lowest anisotropy roughness among the tested surfaces.

Figure 7 shows that both ball-burnishing strategy (2) and (6) are able to improve the arithmetic roughness of the machined surface profile Ra by crushing the roughness picks and pushing them by plastic deformation in the hollow. Thereby, they improve the surface roughness and remove in the same time the maximum potential future priming sites of surface cracks (hollow) which is predicted by the reduction of the mean spacing of profile irregularities $\mathrm{Sm}$.

Figure 8 shows that all strategies are able to improve the roughness parameter Sm along both $X$ - and $Y$-axes, but the best contribution is assigned to the strategy (6) along the $X$-axes. The application of this strategy has been able to reduce the mean spacing of machining profile irregularities along the $X$-axes from $35.48 \mu \mathrm{m}$ in to 23.18 after finishing, that is to say a gain of $35 \%$.

In addition to the strategies (2), (4), and (5), the strategy (6) remains among the best to improve the roughness $\mathrm{Sm}$ variable along the $Y$-axis by reducing it from $27.09 \mu \mathrm{m}$ for machined surface profil to $17.1 \mu \mathrm{m}$ after treatment, i.e., an enhancement of $37 \%$.

Each ball-burnishing strategy developed in this research has its own potential and power to reduce the peaks and 
Fig. 5 Comparison of roughness parameters of treated surfaces with six different ball-burnishing strategies, a along the $X$-axes and b along the $Y$-axes
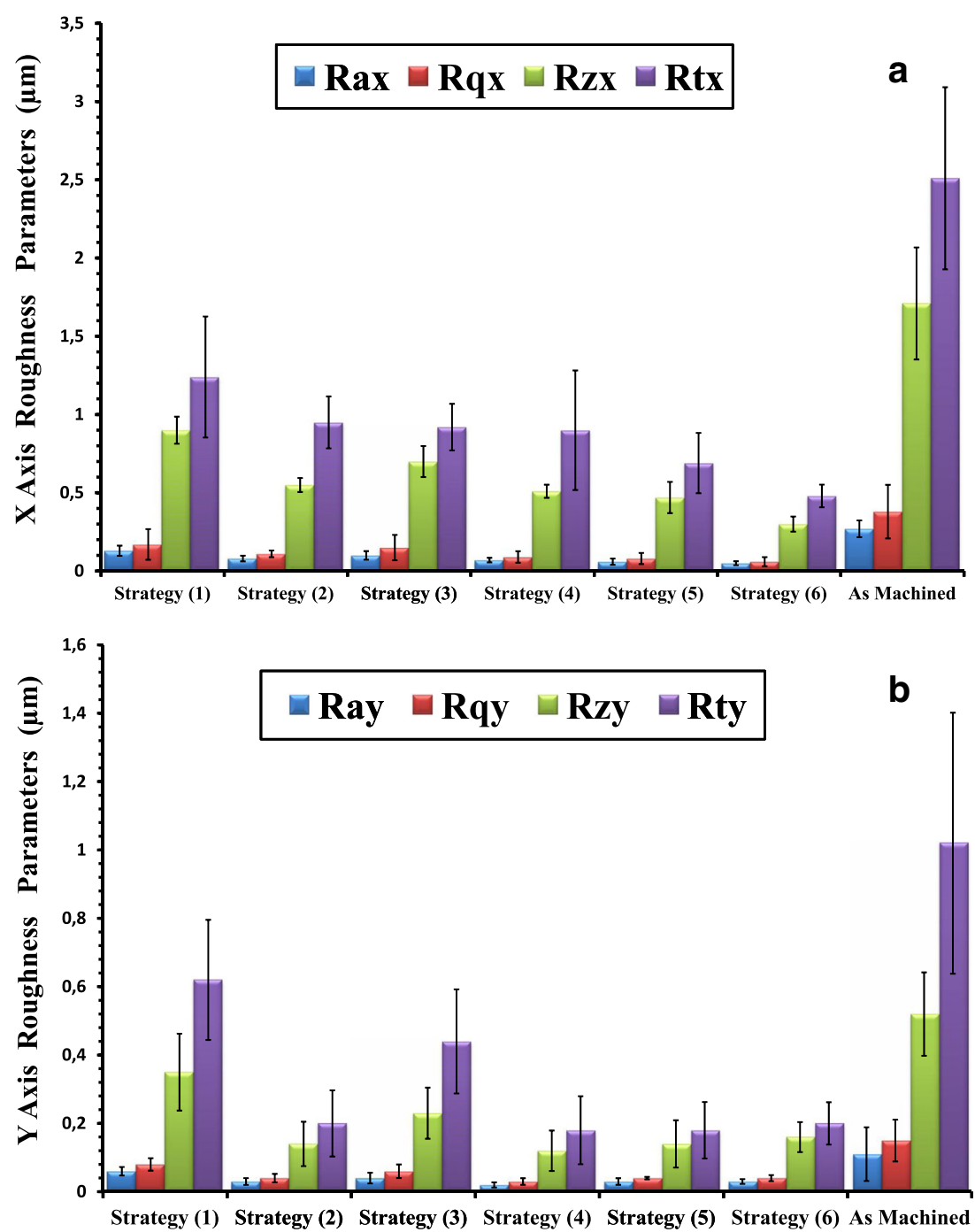

roughness hollows. That is to say, each strategy work hardened machined surface in a way different from other strategies and depends on the kind of ball-burnishing used strategy.

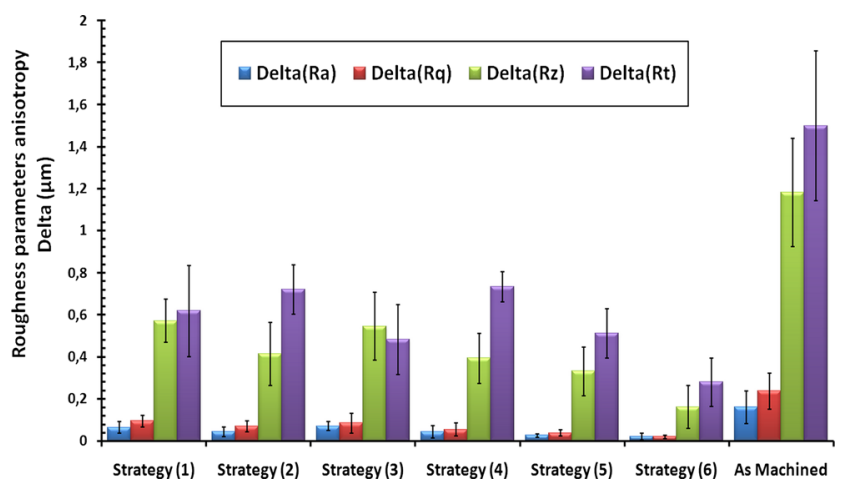

Fig. 6 Roughness parameters anisotropy of treated surfaces with six different ball-burnishing strategies $D\left(R_{i}\right)=\left(R_{i x}-R_{i y}\right)$

\subsection{Surface hardness}

\subsubsection{Superficiel hardness}

The instrumented Martens Hardness test was conducted in this study under the parameters indicated in Table 4 and was used for the measurements of macro surface hardness of the tested surfaces Fig. 9.

The measurements show that all ball-burnishing strategies developed in this study are able to improve the macro surface hardness of the machined surface. Ball-burnishing strategies (1) and (2) in two successive and perpendicular passes to the machining direction have a better potential for hardening of the machined surfaces that the strategies in two crossed passes.

The strategy (6) is the best of cross strategies which give surface macro hardness comparable to that given by the two strategies in two successive passes perpendicular to the 


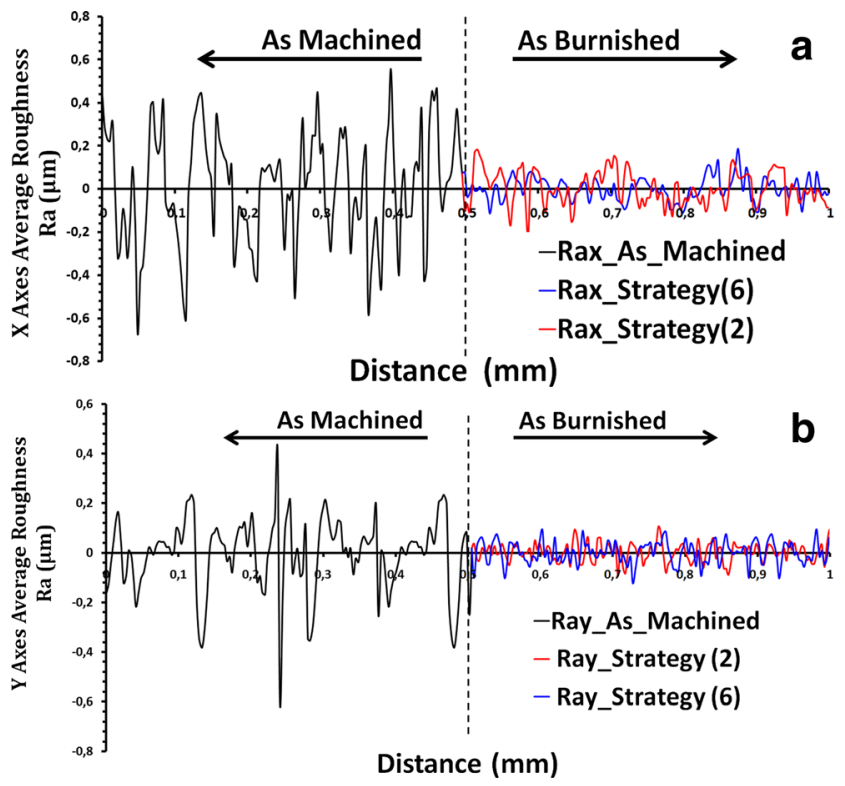

Fig. 7 Comparison of the average roughness profiles of the ballburnished surface with strategies ( 6 ) and (2), and the machined surface, a along the $X$-axes and $\mathbf{b}$ along the $Y$-axes

machining direction. For a load about $50 \mathrm{~N}$, the gain in macro surface hardness is successively $42 \%$ for strategy (1), $39 \%$ for strategy (2), and $35 \%$ for strategy (6). This indicates that the strategy (6) resists nearly in the same way as the two noncrossing strategies (1) and (2) to the indenter penetration.

\subsubsection{Sublayers hardness}

The evaluation of the hardness gradient in the sub-layer of both ball-burnishing and machining surfaces was carried by the nanoindentation tests which have been performed with a XP MTS instrument (USA) mounted with a three sided pyramid (Berkovich tip). The tip area function has been calibrated using a reference material of known modulus (fused quartz, $E=72 \mathrm{GPa}$ ). Load-displacement curves have been analyzed using the Oliver and Pharr method [24]. The loading profile used was as follows: a first load at $500 \mathrm{mN}$ in $30 \mathrm{~s}$, then a

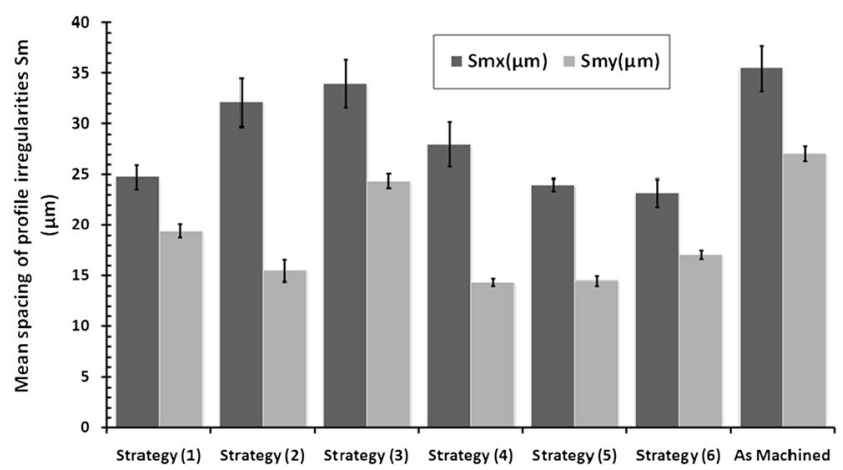

Fig. 8 Contribution of the six ball-burnishing strategies on the improvement of the mean spacing of profile irregularities Sm
Table 4 Martens hardness test parameters

Martens hardness test

\begin{tabular}{ll}
\hline Parameters & Qualities \\
\hline Determining mode of zero-point & Second-degree polynomial \\
Load & $50 \mathrm{~N}, 100 \mathrm{~N}, 200 \mathrm{~N}$ \\
Waiting time at the load point & $12 \mathrm{~s}$ \\
Speed of the contact point & $1 \mathrm{~mm} / \mathrm{min}$ \\
Charge velocity & $100 \mathrm{~N} / \mathrm{min}$ \\
Discharge velocity & $100 \mathrm{~N} / \mathrm{min}$ \\
Deformability machine & $0.0049679 \mu \mathrm{m} / \mathrm{N}$ \\
\hline
\end{tabular}

dwelling time of $12 \mathrm{~s}$ to avoid creep effect during the unloading part, and finally, an unloading part to $0 \mathrm{mN}$ in $30 \mathrm{~s}$.

Nano-hardness measurements were carried out at a depth of $1 \mathrm{~mm}$ as shown in Fig. 10. The results show that:

$\checkmark$ There is no change in hardness for the machined surface along a depth of $1 \mathrm{~mm}$ under layer (1.6 GPa).

$\checkmark$ All burnishing strategies developed in this study provide a clear and significant improvement in hardness layer extending over a depth of $500 \mu \mathrm{m}$.

$\checkmark$ Besides strategy (3), burnishing strategies in two crossed passes (4), (5) and (6) are better than the two strategies in two successive passes (1) and (2) in their improvement hardness under-layer of ball burnished surfaces.

$\checkmark$ At the depth of $100 \mu \mathrm{m}$, the strategy (6) acquires the highest sub-layer hardness material (2.07 GPa).

\section{Discussion}

\subsection{Ball-burnishing strategies effects on surface roughness}

The machined surface texture and topography are a result of the nature of the used cutting tool and cutting conditions mentioned above in Table 3. During machining of

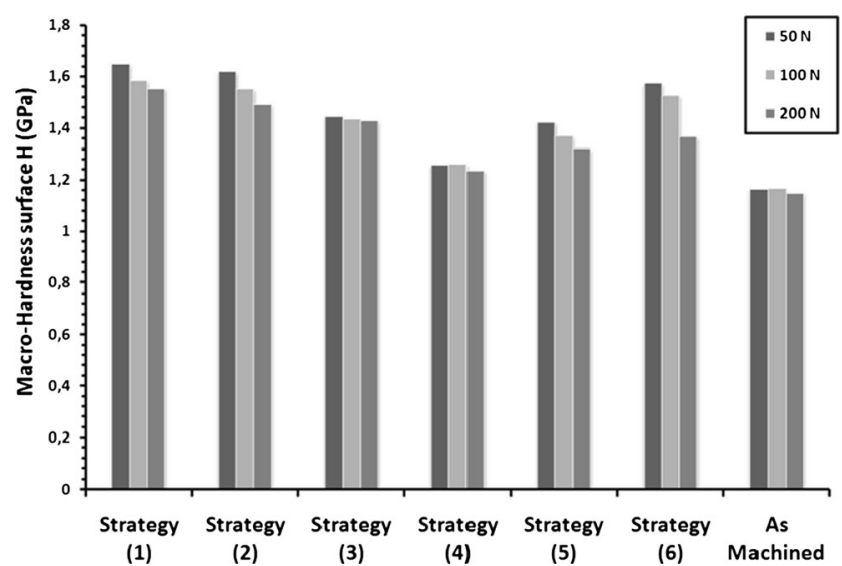

Fig. 9 Macro-hardness surface H (GPa) for different charge applications 


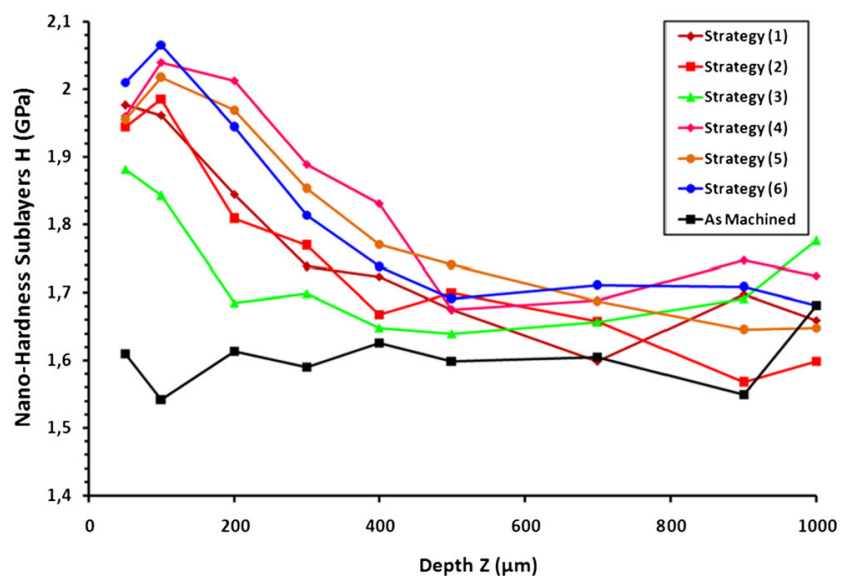

Fig. 10 Nano-hardness sublayers of treated and machined surfaces

the surface, the material tearing forms roughness peaks and hollows. Then, the observed machining marks take the shape of arches which are periodically spaced in the feed direction of cutting tool (Fig. 11 (M)). These latter are the white arches observed in the micrograph of the machined surface Fig. $12(\mathrm{M})$. The white arcs are a not ripped flakes formed during the cutting phase of the material surface. They remain attached to the roughness peaks which are characterized by their low mechanical strength (Fig. $12(\mathrm{M})$ ).

Therefore, they can be cold work-hardened during an under pressure rigid element passage. This is the reason for what the machined surface roughness profile is called a saw-tooth or a "jaggedness" texture as mentioned in Salahshoor and Guo study [16]. Then, the roughness peaks form a mechanically weakest geometric link of the roughness profile able to be deformed plastically and then pushed into hollows.

This geometrical irregularity of the machined surface roughness profile is reduced and eliminated by all ballburnishing strategies developed in this research. So, that is the reason for what we notice the total elimination of white arches in Fig. 12. As a result, a higher light reflection capability is given to treated surfaces by ball burnishing, and then, we obtain mirror-like surfaces as shown in Fig. 4. But, we also note that except strategy (6) (Fig. 12 (S6)), in which all traces
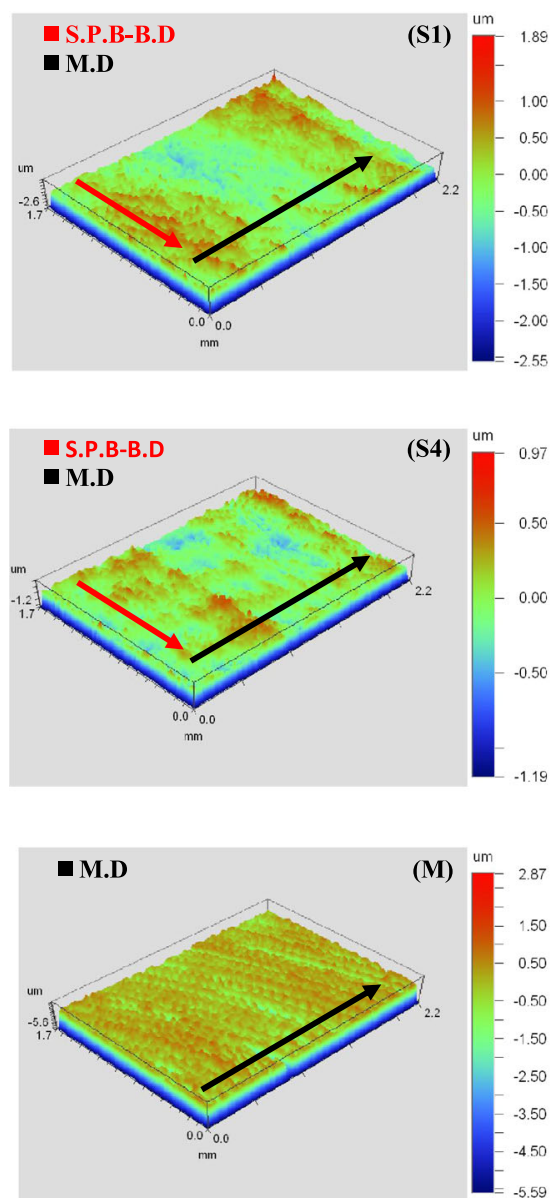
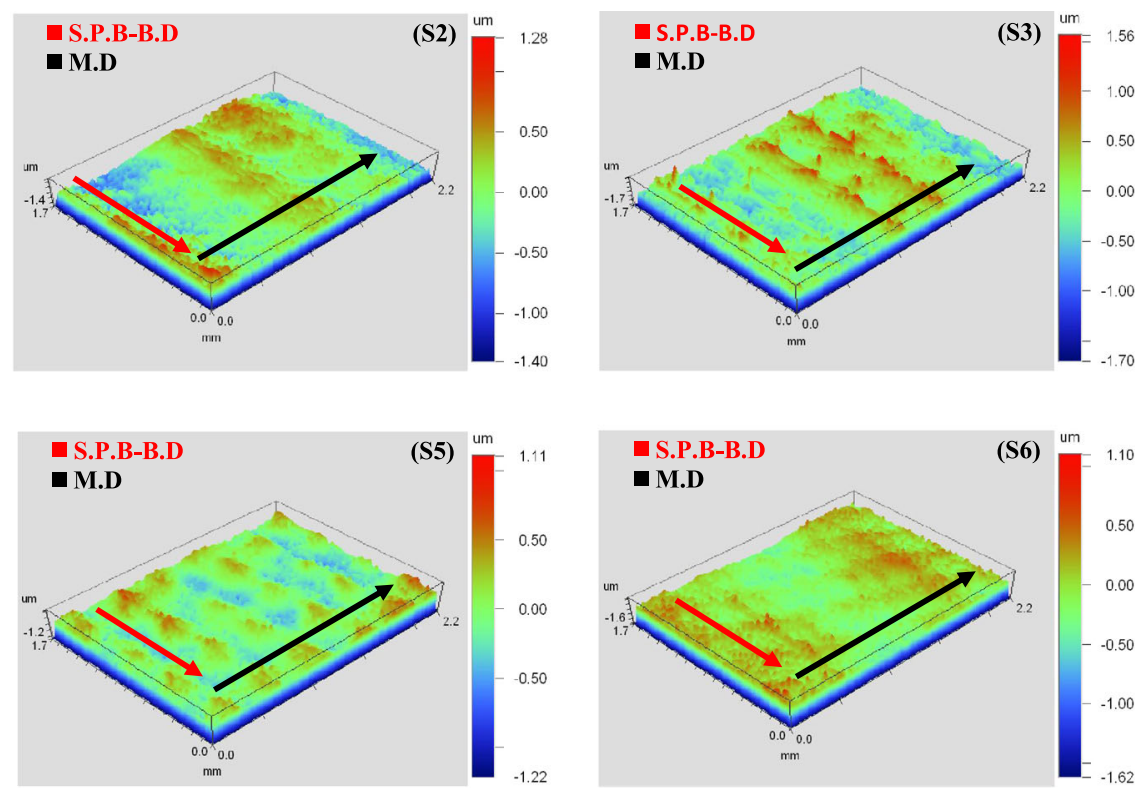

Fig. 11 Surface texture, As Machined (M), strategy $1(S 1)$, strategy $2(S 2)$, strategy $3(S 3)$, strategy $4(S 4)$, strategy 5 (S5), and strategy 6 (S6). M.D milling direction, S.P.B-B.D second pass of ball-burnishing direction 

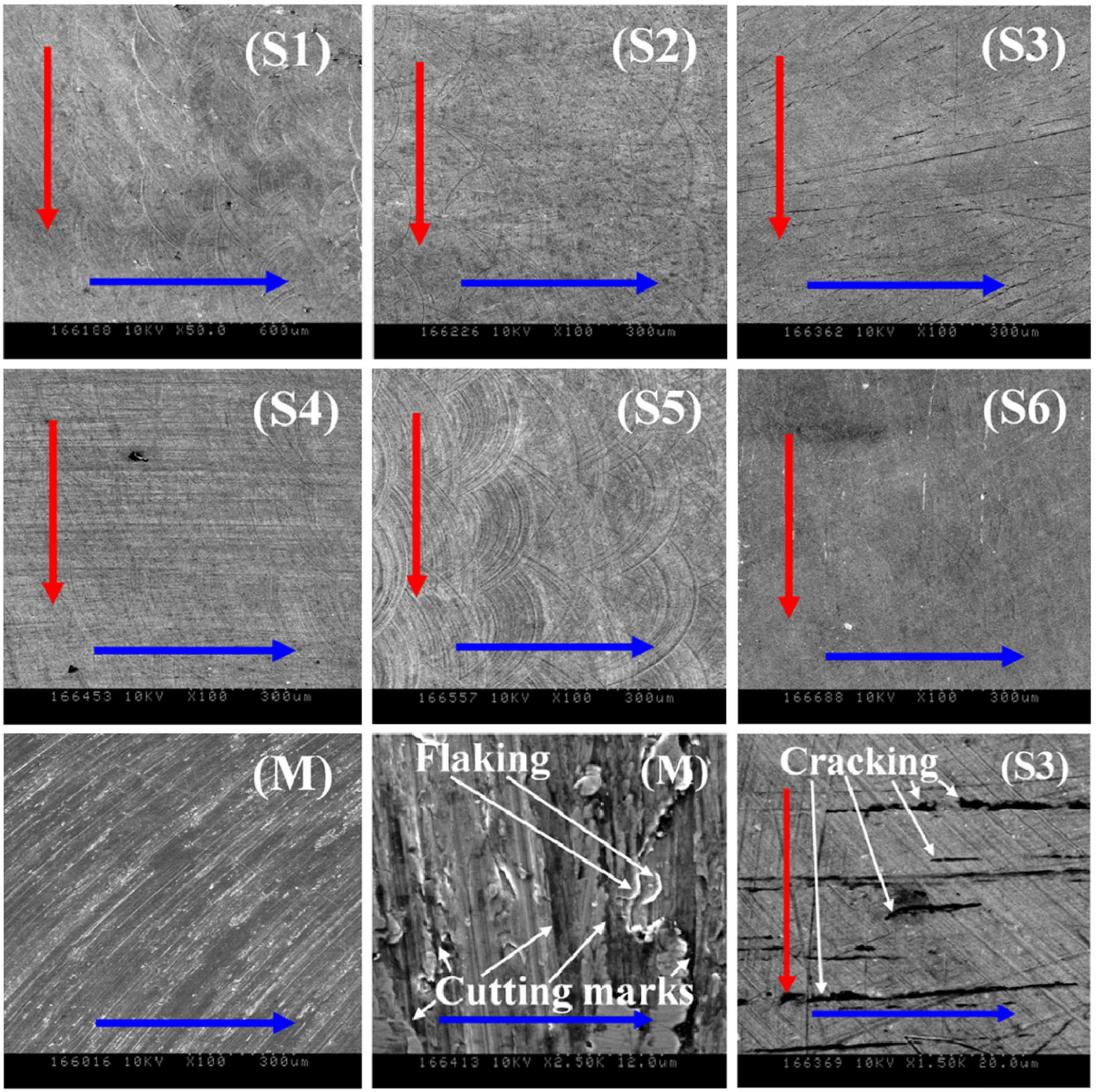

Fig. 12 Scanning electron micrographs of the studied surfaces, As Machined (M), strategy $1(S 1)$, strategy 2 (S2), strategy 3 (S3), strategy $4(S 4)$, strategy 5 (S5), and strategy 6 (S6). Milling direction (blue arrow) and second pass of ball-burnishing direction (red arrow)

are practically striped, the rest of ball-burnishing strategies fail to remove the cutting tool marks.

By exception of the strategy (3), the ball-burnishing strategies in two crossed passes developed in this work have unequal reducing power of geometrical irregularities of the machined surface profile larger than that in two successive and perpendicular passes to the machining direction. This unequal power of the roughness reduction is a result of the difference between the ball-burnishing strategies designed for the mechanical treatment of machined surfaces (Fig. 3). This difference is due to the manner in which it is produced via the crushing of the machined surface roughness peaks by plastic deformation imposed by the used strategy. In addition, the best reducing power of the treated surfaces roughness is entrusted to strategy (6) as shown in both Fig. 11 (S6) and Fig. 12 (S6).
Treated surfaces textures obtained when using the ballburnishing strategies in two successive and perpendicular passes to the machining direction (strategy (1) and strategy (2)) form an undulation defects perpendicular to the machining direction ( $X$-axis) (Fig. 11 (S1) and (S2)). This drawback observed with strategies (1) and (2) is nonexistent for the finished surfaces with the other ballburnishing strategies in two crossed passes.

The distribution of residual peaks formed following the ball-burnishing application is more homogeneous for surfaces having undergone a ball-burnishing treatment according to the strategies in two crossed passes (Fig. 11 (S3, S4, S5, and S6)). Strategy (6) showed in Fig. 11 (S6) has a better uniformity in the flow of material to the surface. So, as a result, it gives the best roughness among the treated surfaces. 
The worst roughness is obtained by the strategy (1) for ballburnishing strategies in two perpendicular passes to the machining direction and is also obtained by the strategy (3) for the strategies in two crossed passes as shown in Fig. 5a, b. This is due to the nature of the ZIG/ZAG cycle used for the development of these two strategies. Applying one ZIG/ZAG pass is equivalent to applying a two SEUIL passes, that is to say that both strategies (1) and (3) are not made in two passes but in four ball-burnishing passes. But, the increase of the ball-burnishing passes number increases roughness and decreases the surface hardness as shown in both works of Sequera et al. [6] and Hassan et AI-Wahhab [12]. Then as a result, the use of the both strategies (1) and (3) gives poor quality surfaces in comparison to others of the same nature. This is due to the fact that the addition of several passes produces an excess of surface hardening, which causes the damage of the surface by chipping following the formation of micro cracks as shown in Fig. 12 (S3) and the study of El-Axir et al. [8]. Also, the latter observation predicted by an increasing in the roughness and deterioration of surface hardness after superficial micro cracks creation with the application of the two crossed ZIG/ZAG passes strategy is in a good agreement with the Salahshoor and Guo work [16]. So, by exception for the latter kind of ball-burnishing strategy, the multiple advantages of the ball-burnishing strategies in two crossed passes make them favored to be used for a better and precise finishing of machined flat surfaces.

\subsection{Ball-burnishing strategies effects on surface hardness}

The best hardness of the treated surfaces by ball burnishing is obtained by applying the strategies in two successive and perpendicular passes to the cutting direction Fig. 9. This result is in a good agreement with the work of Salahshoor and Guo [16].

For the strategies in two successive and perpendicular passes to the machining direction, the strategy (1) gives a higher surface hardness to that given by the strategy (2). This is due to the fact that the application of two successive ZIG/ZAG passes is equivalent to the application of four passes in SEUIL. Consequently, strategy (1) has the great potential for superficial hardening described through a better surface hardness. In addition, we note that the strategy (6) is the best crossed strategies in two crossed passes to give a surface hardness comparable to that given by the strategies (1) and (2) designed by two successive and perpendicular passes to the machining direction.

In sub-layer, all ball-burnishing strategies introduce a hardness improvement in depth of the treated surfaces up to $500 \mu \mathrm{m}$ as shown in Fig. 10. But, we note that with the exception of the strategy (3), strategies (4), (5), and (6) give greater hardness levels than those given by the strategies (1) and (2). At the depth of $100 \mu \mathrm{m}$, strategy (6) shows the higher sub-layer hardness level (2.07 Gpa).
The poor contribution in hardness subsurface enhancement is given by the strategy (3) as shown in Fig. 10. As explained previously, the application of two ball-burnishing ZIG/ZAG passes is equivalent to the application of four ball-burnishing ones. This leads to the degradation of surface and sub-layers hardness by flaking and cracking formation as shown in Fig. 12 (S3).

\section{Conclusion}

In this experimental study, ball burnishing of machined flat surfaces was mastered by following six new strategies in two successive or crossed passes of the 2017A-T451 aluminum alloy. Then, for these chosen machining conditions and ballburnishing optimum factors, the characterization of the treated surfaces integrity reveals the following conclusions:

-Ball-burnishing strategies in two crossed passes have the best potential for improving the roughness of the machined flat surfaces. On the other hand, ball-burnishing strategies in two successive passes are the best to use for improving the surface hardness.

-Because of its hardening power of geometric irregularities of the surface roughness profile, the strategy 6 (strategy ZIG/ ZAG_SEUIL in two crossed passes) is the best to be used for having the best surface quality predicted by an $81 \%$ improvement in the surface roughness parameters while giving $35 \%$ improvement in the surface hardness comparable to that given by the strategies in two successive passes.

-All ball-burnishing strategies have shown sub-layer hardening potential to a depth of $500 \mu \mathrm{m}$, revealed by an improvement in the hardness of the substrate. Except for strategy (3), ball-burnishing strategies in two crossed passes (4), (5), and (6) are better than the two strategies in two successive passes (1) and (2) in their improved under-layer hardness. But, the best level of hardness under layer $(2.07 \mathrm{GPa})$ at a depth of $100 \mu \mathrm{m}$ is entrusted to strategy (6).

Acknowledgments The authors would like to thank the Higher Institute of Technological Studies (ISET) (KEF City, Tunisia) and the Arts et Metiers ParisTech (ENSAM) LILLE (Lille City, France) for supporting this research program on ball-burnishing process.

\section{References}

1. Loh NH, Tam SC (1988) Effects of ball burnishing parameters on surface finish - a literature survey and discussion. Precis Eng 10(4): 215-220. doi:10.1016/0141-6359(88)90056-6

2. Hassan AM, Al-Bsharat AS (1996) Improvements in some properties of non-ferrous metals by the application of the ball-burnishing process. J Mater Process Technol 59:250-256. doi:10.1016/09240136(95)02149-3

3. López de Lacalle LN, Lamikiz A, Sánchez JA, Arana JL (2007) The effect of ball burnishing on heat treated steel and Inconel 718 
milled surfaces. Int J Adv Manuf Technol 32(9-10):958-968. doi:10.1007/s00170-005-0402-5

4. Travieso-Rodríguez JA, Dessein G, González-Rojas HA (2011) Improving the surface finish of concave and convex surfaces using a ball burnishing process. Mater Manuf Process 26(12):1494-1502. doi:10.1080/10426914.2010.544819

5. Tadic B, Todorovic PM, Luzanin O, Miljanic D, Jeremic BM, Bogdanovic B, Vukelic D (2013) Using specially designed high-stiffness burnishing tool to achieve high-quality surface finish. Int J Adv Manuf Technol 67(1-4):601-611. doi:10.1007/s00170-012-4508-2

6. Sequera A, Fu CH, Guo YB, Wei XT (2014) Surface integrity of inconel 718 by ball burnishing. J Mater Eng Perform 23(9):33473353. doi:10.1007/s11665-014-1093-6

7. López de Lacalle LN, Rodríguez A, Lamikiz A, Celaya A, Alberdi R (2011) Five-axis machining and burnishing of complex parts for the improvement of surface roughness. Mater Manuf Process 26(8): 997-1003. doi:10.1080/10426914.2010.529589

8. El-Axir MH, Othman OM, Abodiena AM (2008) Study on the inner surface finishing of aluminum alloy 2014 by ball burnishing process. J Mater Process Technol 202:435-442. doi:10.1016/j. jmatprotec.2007.10.040

9. Bouzid W, Tsoumarev O, SaÏ K (2004) An investigation of surface roughness of burnished AISI 1042 steel. Int J Adv Manuf Technol 24:120-125. doi:10.1007/s00170-003-1761-4

10. Akkurt A (2011) Comparison of roller burnishing method with other hole surface finishing processes applied on AISI 304 austenitic stainless steel. J Mater Eng Perform 20:960-968. doi:10.1007/s11665-010-9718-X

11. Hassan AM (1997) The effects of ball- and roller-burnishing on the surface roughness and hardness of some non-ferrous metals. J Mater Process Technol 72:385-391. doi:10.1016/S0924-0136(97)00199-4

12. Hassan AM, AI-Wahhab OM (1998) Surface characteristics of some roller burnished non-ferrous components. Mater Manuf Process 13(4):505-515. doi:10.1080/10426919808935272

13. H Amdouni, H Bouzaiene, A Montagne, M Nasri, A Iost. Modeling and optimization of a ball-burnished aluminum alloy flat surface with a crossed strategy based on response surface methodology. Int J Adv Manuf Technol. 2016; 1-14. DOI 10.1007/s00170-016-8817-8
14. Shiou F-J, Chen C-H (2003) Freeform surface finish of plastic injection mold by using ball-burnishing process. J Mater Process Technol 140:248-254. doi:10.1016/S0924-0136(03)00750-7

15. Loh NH, Tam SC, Miyazawa S (1989) A study of the effects of ball burnishing parameters on surface roughness using factorial design. J Mech Work Technol 18:53-61. doi:10.1016/0378-3804(89)90109-5

16. Salahshoor M, Guo YB (2011) Surface integrity of biodegradable magnesium-calcium orthopedic implant by burnishing. J Mech Behav Biomed Mater 4(8):1888-1904. doi:10.1016/j. jmbbm.2011.06.006

17. Prevéy PS, Cammett J (2001) Low cost corrosion damage mitigation and improved fatigue performance of low plasticity burnished 7075-T6. J Mater Eng Perform 10(5):548-555. doi:10.1361/105994901770344692

18. Hassan AM, Al-Dhifi ZS (1999) Sulieman. Improvement in the wear resistance of brass components by the ball burnishing process. J Mater Process Technol 96(1-3):73-80. doi:10.1016/S0924-0136(99)00254-X

19. Rodríguez A, López de Lacalle LN, Celaya A, Lamikiz A, Albizuri J (2012) Surface improvement of shafts by the deep ball-burnishing technique. Surface \& Coatings Technology 206:2817-2824. doi:10.1016/j.surfcoat.2011.11.045

20. Rajasekariah R, Vaidyanathan S (1975) Increasing the wearresistance of steel components by ball burnishing. Wear 34:183188. doi:10.1016/0043-1648(75)90064-2

21. Neema ML, Pandey PC (1980) Investigation of the performance characteristics of cold-worked machined surfaces. Wear 60:157166. doi:10.1016/0043-1648(80)90256-2

22. Hassan AM, Maqableh AM (2000) The effects of initial burnishing parameters on non-ferrous components. J Mater Process Technol 102:115-121. doi:10.1016/S0924-0136(00)00464-7

23. Shiou F-J, Hsu C-C (2008) Surface finishing of hardened and tempered stainless tool steel using sequential ball grinding, ball burnishing and ball polishing processes on a machining Centre. J Mater Process Technol 205:249-258. doi:10.1016/j.jmatprotec.2007.11.244

24. Oliver WC, Pharr GM (1992) An improved technique for determining hardness and elastic modulus using load and displacement sensing indentation experiments. J Mater Res 7:1564-1583. doi:10.1557/JMR.1992.1564 